\title{
A Family of Auxiliary Switch ZVS-PWM DC-DC Converters with Coupled Inductor
}

\author{
N.Lakshminarasamma, V.Ramanarayanan \\ Affiliation \\ Electrical Engineering/Indian institute of science \\ India \\ lakshmin@ee.iisc.ernet.in, vram@ee.iisc.ernet.in
}

\begin{abstract}
A novel auxiliary switch DC-DC converter with coupled inductor is presented in this paper. The proposed circuit achieves loss-less switching for both the main and auxiliary switches without increasing the main device current/voltage rating. A tapping in the pole inductor is added for the purpose of commutation. The proposed circuit is capable of operation at elevated switching frequencies of several hundreds of $\mathrm{KHz}$, high and low power levels with wide range of load variations. In the sections that follow, theoretical analysis and operating principle of the proposed circuit is outlined through the example of buck converter. Simulation and experimental results of 33 watt, $400 \mathrm{KHz}$ boost converter are presented. The proposed circuit is applicable to all isolated and non-isolated DC-DC converters. The performance and the design equations of the ZVS are identical for all types of DC-DC converters when the throw voltage and the pole current are properly defined.
\end{abstract}

\section{INTRODUCTION}

he constant demand for smaller and lighter power DCT DC converters is pushing the switching frequencies well into Mega Hertz range. Such high frequency switching is possible by resonant topologies ([2] - [11]). In contrast to the sharp-edged switching waveforms of PWM converters, these resonant converter topologies feature smooth waveforms resulting in reduced switching losses and less interference.

Quasi-resonant converters introduced (QRC) in [3] reduce the switching losses in PWM converters operating at high switching frequency. The control for this family of converters is by variable switching frequency. However the switches in QRC are subjected to high voltage stress and/or high current stress [4].

In zero-voltage transition (ZVT) introduced in [6], the VA ratings of the switches are same as that of the source voltage and load current. However, the auxiliary switches still have switching losses during turn-off [11].

In auxiliary resonant commutated pole converter (ARCP) introduced in [5], the VA ratings of the main switch are same as that of the source voltage and load current. These converters have advantages of traditional PWM converters. The resonant current is not carried by the main switch [10]. Active clamp converters, introduced in [7] have some constraints. Zero voltage switching in these converters is load dependent. VA rating of the switches is higher than the source voltage and the load current [9].

The proposed circuit [12] addresses the above problems and maintains the advantages of traditional PWM converters.
There is an additional winding on the same core of the filter inductor. The novelty in the proposed circuit is the method of generating the voltage required to ensure ZCS conditions for the auxiliary switch. The switching transitions of both the active switch $\mathrm{S}$ and auxiliary switch $S_{a}$ are loss-less. The switching frequency is constant in the proposed converter. The VA ratings of the active switch S are same as that of the source voltage and load current.

The paper is organized as follows: Section II presents the generic requirements of ZVT PWM Converters with auxiliary switch. Section III presents the mathematical analysis of the performance of a sample buck converter with auxiliary switch circuit. Section IV and V presents the simulation and experimental results of 33 Watt, $400 \mathrm{KHz}$ converter. Application of proposed auxiliary circuit to all DC-DC converters is presented in section VI. Section VII gives the conclusion and the references.

\section{ZVT PWM Converters Mechanism}
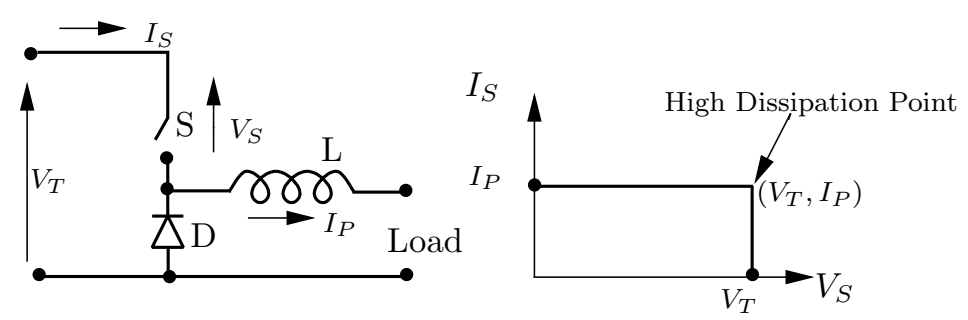

Fig. 1. A typical switching pole in a power converter

Fig. 1 shows the basic switching element common to all switching power converters [1]. The throw voltage $V_{T}$, and the pole current $I_{P}$ are defined as shown in Fig. 1. The active and the passive switches are $\mathrm{S}$ and $\mathrm{D}$ respectively. The switch voltage $V_{S}$ and the switch current $I_{S}$ trajectories are shown in Fig. 1. Every turn-on and turn-off process transits through the high dissipation point of $\left(V_{T}, I_{P}\right)$. This results in high switching losses which is proportional to the switching frequency. The proposed scheme introduces an auxiliary circuit connected in parallel to the active switch. The auxiliary circuit consists of auxiliary switch $S_{a}$, a series diode $D_{a}$, a set of resonant elements $L_{a}$ and $C_{a}$ and a dependant voltage source $V_{a}$ as shown in Fig. 2. The auxiliary circuit when switched properly, ensures lossless switching. 


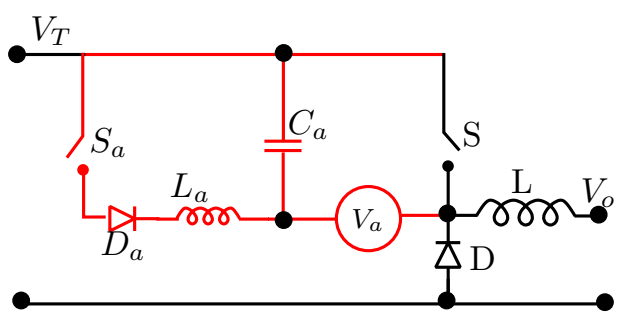

Fig. 2. Auxiliary circuit cell

\section{A. Auxiliary circuit with $V_{a}=0$}

Consider the circuit shown in Fig. 3. The steady-state ZVT waveforms are shown in Fig. 4.

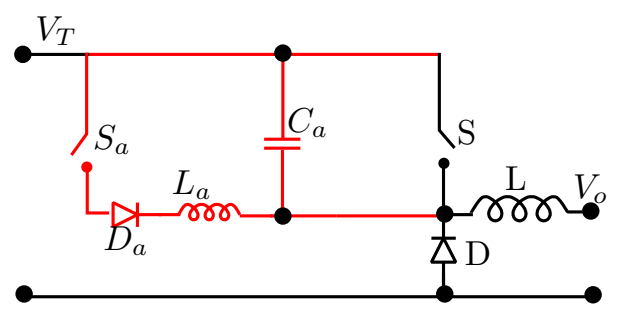

Fig. 3. Auxiliary circuit cell with $V_{a}=0$

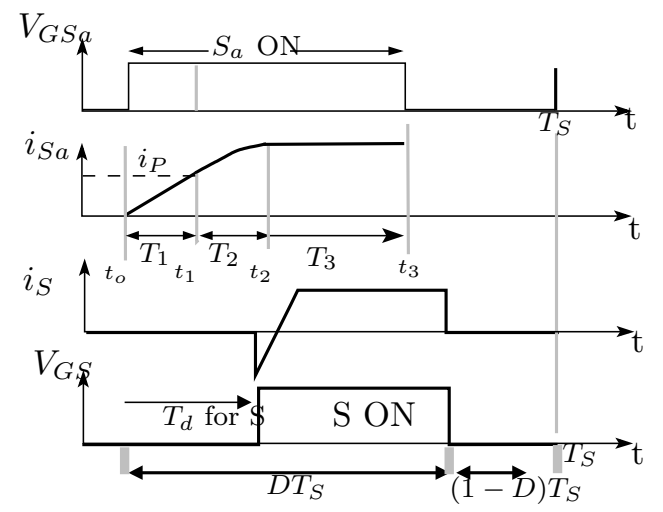

Fig. 4. Switching transitions of the auxiliary circuit with $V_{a}=0$

Interval $\mathbf{0}\left(t<t_{o}\right)$ : The load current is free-wheeling through the passive switch $\mathrm{D}$; resonant capacitor $C_{a}$ is charged to $V_{T}$. The auxiliary switch $S_{a}$ and main switch $\mathrm{S}$ are in OFF state. This state is just prior to commutation of current from passive switch $\mathrm{D}$ to active switch $\mathrm{S}$.

Interval $1\left(t_{o}<t<t_{1}\right)$ : This interval begins when the

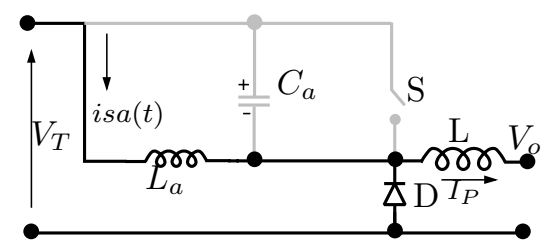

Fig. 5. Auxiliary circuit cell with $V_{a}=0$ : Interval 1

auxiliary switch $S_{a}$ is turned-on at $t=t_{o}$. The turn-on of the auxiliary switch $S_{a}$ is zero current. The equivalent circuit is shown in Fig. 5 with $I_{L a}\left(t_{o}\right)=0$ as the initial condition of resonant inductor. The load current is freewheeling through the passive switch D. The current in the auxiliary switch increases linearly as in Eq. 1.

$$
i_{s a}(t)=\frac{V_{T}}{L_{a}}\left(t-t_{o}\right) ; \text { where } t_{o}<t<t_{1}
$$

At $t=t_{1}$, when $i_{s a}(t)$ reaches $I_{P}$, the passive switch $\mathrm{D}$ turns-off.

$$
T_{1}=\left(t_{1}-t_{o}\right)=\frac{I_{P} L_{a}}{V_{T}}
$$

Interval $2\left(t_{1}<t<t_{2}\right)$ :

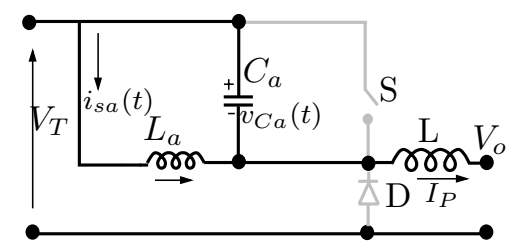

Fig. 6. Auxiliary circuit cell with $V_{a}=0$ : Interval 2

The turn-off of the passive switch $\mathrm{D}$ is followed by the resonant interval. The resonant inductor $L_{a}$ and the resonant capacitor $C_{a}$ resonate during this interval. The equivalent circuit in this interval is shown in Fig. 6.

$$
i_{S a}(t)=I_{P}+V_{T} \sqrt{\frac{C_{a}}{L_{a}}} \sin \left(\omega\left(t-t_{1}\right)\right)
$$

$v_{C a}(t)=V_{T} \cos \left(\omega\left(t-t_{1}\right)\right) ; \omega=\frac{1}{\sqrt{L_{a} C_{a}}} ;$ where $t_{1}<t<t_{2}$

At $t=t_{2}$, when $v_{C a}(t)$ reaches zero, the body diode of the main switch $\mathrm{S}$ turns-on. The main switch $\mathrm{S}$ can be now turned-on with zero voltage switching.

$$
T_{2}=\left(t_{2}-t_{1}\right)=\frac{\pi}{2} \sqrt{L_{a} C_{a}}
$$

Interval $3\left(t>t_{2}\right)$ :

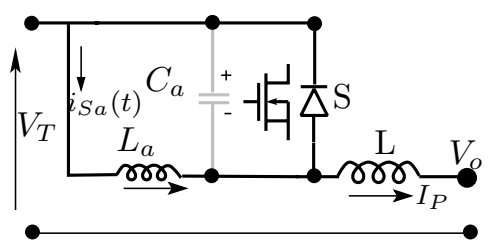

Fig. 7. Auxiliary circuit cell with $V_{a}=0$ : Interval 3

The equivalent circuit following $t=t_{2}$ is shown in Fig. 7 . However, the turn-off of $S_{a}$ under this condition will be hard with switching overvoltage on account of the current in $L_{a}$ being interrupted. This is undesirable.

It is observed that, for the auxiliary circuit with $V_{a}=0$, the turn-on of the auxiliary switch $S_{a}$ is at zero-current. The turn-off transition of the auxiliary switch $S_{a}$ is lossy.

\section{B. Auxiliary circuit with $V_{a} \neq 0$}

It is seen that the turn-off of auxiliary switch $S_{a}$ is lossy with $V_{a}=0$. We may use an auxiliary source $V_{a}$ of appropriate polarity in order to obtain loss-less turn-off of the auxiliary switch $S_{a}$ as well. Such a circuit, operating waveforms and the equivalent circuit are given in the following. 


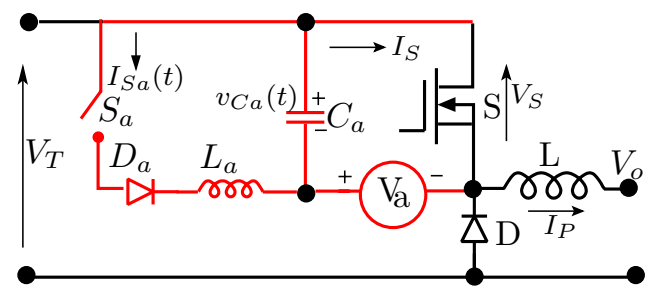

Fig. 8. Auxiliary circuit with $V_{a} \neq 0$

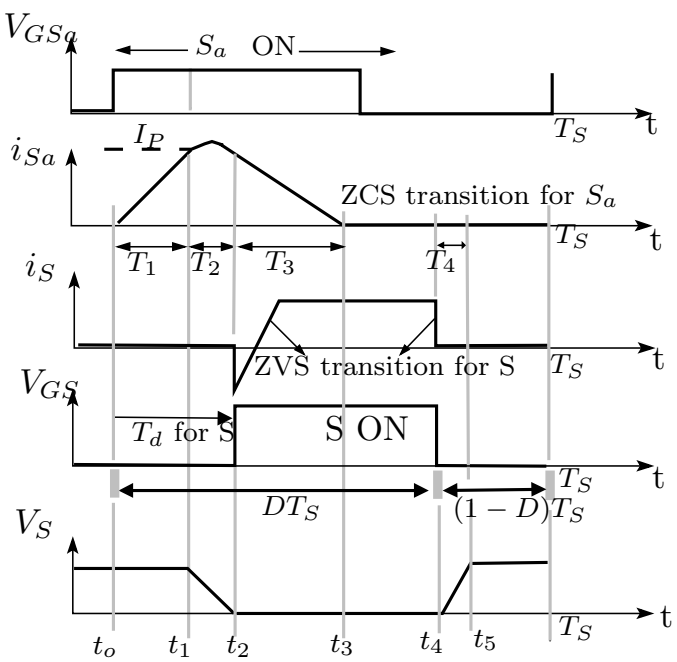

Fig. 9. Switching transitions of the auxiliary circuit with $V_{a} \neq 0$

Fig. 8 shows the auxiliary circuit with the auxiliary source $V_{a} \neq 0$. The transients intervals and the steady-state waveforms are shown in Fig. 9.

Interval $0\left(t<t_{o}\right)$ : The load current is free-wheeling through the passive switch $\mathrm{D}$; resonant capacitor $C_{a}$ is charged to $V_{T}$. The auxiliary switch $S_{a}$ and main switch $\mathrm{S}$ are in $\mathrm{OFF}$ state. This state is just prior to commutation of current from passive switch $\mathrm{D}$ to active switch $\mathrm{S}$.

Interval $1\left(t_{o}<t<t_{1}\right)$ : At instant $t=t_{o}$, auxiliary switch $S_{a}$ is turned-on with $I_{L a}\left(t_{o}\right)=0$ as the initial current of resonant inductor $L_{a}$. The current in the auxiliary switch will raise with a slope of $\frac{V_{T}+V_{a}}{L_{a}}$ as in Eq. 6 ( $V_{a}<0$ in this interval ).

$$
i_{s a}(t)=\frac{V_{T}+V_{a}}{L_{a}}\left(t-t_{o}\right) ; \text { where } t_{o}<t<t_{1}
$$

At $\mathrm{t}=t_{1}$, when $i_{s a}(t)$ reaches $I_{P}$, the passive switch $\mathrm{D}$ turns-off.

$$
T_{1}=t_{1}-t_{o}=\frac{I_{P} L_{a}}{V_{T}+V_{a}}
$$

Interval $2\left(t_{1}<t<t_{2}\right)$ : The turn-off of the passive switch $\mathrm{D}$ is followed by the resonant interval. The resonant inductor $L_{a}$ and the resonant capacitor $C_{a}$ resonate during this interval. The current and voltage equations valid during this interval is given below.

$$
\begin{gathered}
i_{S a}(t)=I_{P}+V_{T} \sqrt{\frac{C_{a}}{L_{a}}} \sin \left(\omega\left(t-t_{1}\right)\right) ; \omega=\frac{1}{\sqrt{L_{a} C_{a}}} \\
v_{C a}(t)=\left(V_{T}+V_{a}\right) \cos \left(\omega\left(t-t_{1}\right)\right) ; \text { where } t_{1}<t<t_{2}
\end{gathered}
$$

At end of the interval, $v_{C a}(t)$ reaches $V_{a}$. This forwardbiases the body diode of the main switch $\mathrm{S}$. Thereby the main switch $\mathrm{S}$ can be turned-on with ZVS.

$$
V_{C a}\left(t_{2}\right)=V_{a} ; \omega T_{2}=\omega\left(t_{2}-t_{1}\right)=\cos ^{-1} \frac{-V_{a}}{V_{T}+V_{a}}
$$

The valid solution for $\omega T_{2}$ is from the second quadrant. The qualitative change in introducing the dependent voltage in the auxiliary circuit occurs following the resonant interval $T_{2}$.

Interval $3\left(t_{2}<t<t_{3}\right)$ : We assume that the auxiliary voltage $V_{a}>0$ in this interval (Later we will see how the auxiliary voltage source $V_{a}$ may be obtained). In the auxiliary circuit, the resonant inductor faces a negative voltage during this interval which resets the same in the interval $T_{3}$. At $t=t_{3}$, the inductor current has fallen to zero. The turn-off of the auxiliary switch $S_{a}$ at $\mathrm{t}=t_{3}$, ensures zero current switching. Following the interval $T_{3}$, the gate drive to the auxiliary switch may be turned-off as shown in Fig. 9.

Interval $4\left(t_{4}<t<t_{5}\right)$ : The main switch $\mathrm{S}$ is switchedoff at $t=t_{4}$ i.e at the end of $D T_{S}$. The turn-off of the main switch is at zero voltage, on account of capacitor across the main switch. The voltage across the switch raises slowly thereby reducing the turn-off transition losses.

It is observed that, for the auxiliary circuit with $V_{a} \neq 0$, the switching transitions of both the main and auxiliary switches are lossless.:

\section{Circuit REALization of ZVT MEChanism AND ANALYSIS OF BUCK CONVERTER}

We have observed in section II that it is necessary to obtain a dependent source $V_{a}$ whose magnitude is less than zero during turn-off of the passive switch $\mathrm{D}$ i.e interval $T_{1}$ and greater than zero during reset of the auxiliary switch $S_{a}$ i.e interval $T_{3}$. The magnitude of $V_{a}$ could be same or different during the interval 2 and interval 4 . The generation of the dependent voltage source $V_{a}$ is by the auxiliary winding coupled to the main inductor. Fig. 10 shows the

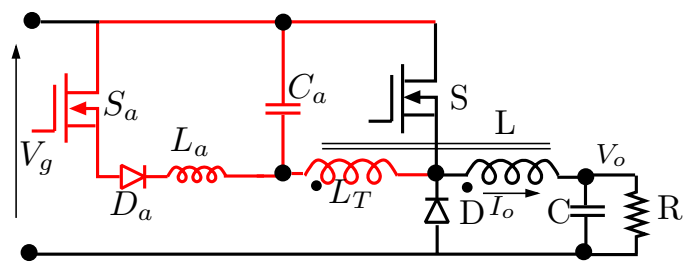

Fig. 10. Buck converter with primitive auxiliary switch commutation circuit

primitive auxiliary circuit for a buck converter employing this method. The commutation process and the mathematical analysis is explained for the buck converter with auxiliary switch. To simplify the analysis, it is considered that, the converter is operating in steady state and the following assumptions are made.

1. All components and devices are ideal. 
2. The output filter inductor $\mathrm{L}$ is large enough to assume that the output current $I_{o}$ is constant.

3. The output capacitor $\mathrm{C}$ is large enough to assume that the output voltage is constant and ripple free.

The turns ratio between $\mathrm{L}$ and $L_{T}$ may be chosen conveniently. The winding $L_{T}$ has to carry the commutation current and reset current only. Therefore the RMS value of this coupled winding will be a small fraction of the current flowing in the main inductor L. Accordingly, this will not demand a higher size of inductor. The complete commutation process and the mathematical analysis are explained below for a buck converter. To simplify the analysis, turns ratio for the coupled inductor ( $\mathrm{L}$ and $L_{T}$ ) is taken to be 1 . Switching sequences are as shown in Fig. 9.

Interval $\mathbf{0}\left(t<t_{o}\right)$ : Prior to time $\mathrm{t}=t_{o}$, the main switch $\mathrm{S}$ and the auxiliary switch $S_{a}$ is in OFF state. The load current is freewheeling through the diode D. The resonant capacitor is charged to voltage $\left(V_{g}+V_{0}\right)$.

Interval $1\left(t_{o}<t<t_{1}\right)$ : This interval begins when the auxiliary switch $S_{a}$ is turned-on with ZCS at $t=t_{o}$. The equivalent circuit is shown in Fig. 11 with $I_{L a}\left(t_{o}\right)=0$ as the initial current of resonant inductor $L_{a}$. The load current is freewheeling through the passive switch D. The current in the auxiliary switch will increase linearly as in Eq. 11.

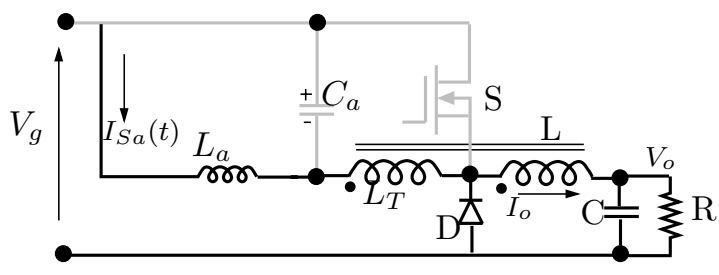

Fig. 11. ZVS buck converter: Interval 1: $\left(t_{o}<t<t_{1}\right)$

$$
i_{s a}(t)=\frac{\left(V_{g}+V_{o}\right)}{L_{a}}\left(t-t_{o}\right)=\frac{V_{g}(1+D)}{L_{a}}\left(t-t_{o}\right)
$$

At $\mathrm{t}=t_{1}$, when $i_{s a}(t)$ reaches $\frac{I_{o}}{2}$, the passive switch $\mathrm{D}$ turns-off.

$$
T_{1}=\left(t_{1}-t_{o}\right)=\frac{I_{o} L_{a}}{2 V_{g}(1+D)}
$$

Interval $2\left(t_{1}<t<t_{2}\right)$ : The turn-off of the passive switch $\mathrm{D}$ is followed by the resonant interval. The resonant elements $L_{a}$ and $C_{a}$ resonate during this interval. This interval ends, when the voltage across the resonant capacitor $v_{C a}(t)$ reaches $\left(V_{o}-V_{g}\right)$. This forward biases the body diode of the main switch $\mathrm{S}$.

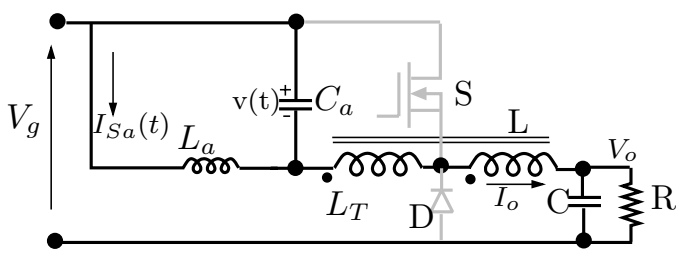

Fig. 12. ZVS buck converter: Interval 2: $\left(t_{1}<t<t_{2}\right)$

$i_{S a}(t)=\frac{I_{o}}{2}+V_{g}(1+D) \sqrt{\frac{C_{a}}{L_{a}}} \sin \left(\omega\left(t-t_{1}\right)\right)$

$$
\begin{gathered}
v_{C a}(t)=V_{g}(1+D) \cos \left(\omega\left(t-t_{1}\right) ; \omega=\frac{1}{\sqrt{L_{a} C_{a}}}\right. \\
V_{C a}\left(t_{2}\right)=V_{o}-V_{g}=-V_{g}(1-D) ; \text { where } t_{1}<t<t_{2} \\
\omega T_{2}=\omega\left(\left(t_{2}-t_{1}\right)\right)=\cos ^{-1}\left[\frac{-(1-D)}{(1+D)}\right] \\
I_{S a}\left(t_{2}\right)=2 V_{g} \sqrt{\frac{C_{a}}{L_{a}}} \sqrt{D}+\frac{I_{P}}{2}
\end{gathered}
$$

At time $t=t_{2}$, body diode of the main switch $\mathrm{S}$ is $\mathrm{ON}$ and main switch $\mathrm{S}$ can now be turned-on with ZVS.

Interval $3\left(t_{2}<t<t_{3}\right)$ : The resonant inductor current flows through the main switch S, auxiliary switch $S_{a}$ and the auxiliary diode $D_{a}$. The trapped energy in the auxiliary circuit inductor $L_{a}$ is recovered into the coupled inductor $L_{T}$. The voltage across the coupled winding is $\left(V_{g}-V_{o}\right)$. The negative voltage across the resonant inductor $L_{a}$ will reset $i_{L a}(t)$ linearly to zero as given by Eq. 18 . Turn-off of the auxiliary switch at $\mathrm{t}=t_{3}$, ensures ZCS.

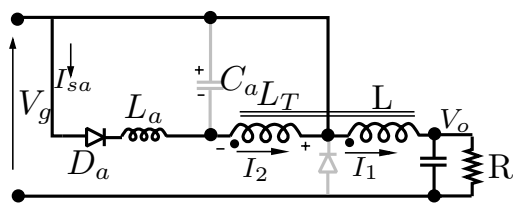

Fig. 13. ZVS buck converter: Interval 3: $\left(t_{2}<t<t_{3}\right)$

$$
i_{S a}(t)=\frac{-V_{g}(1-D)}{L_{a}}\left(t-t_{2}\right)+I_{S a}\left(t_{2}\right)
$$

End of interval $T_{3}$ is when $i_{S a}\left(T_{3}\right)=0$

$$
T_{3}=t_{3}-t_{2}=\sqrt{L_{a} C_{a}} \frac{\sqrt{D}}{(1-D)}+\frac{I_{P} L_{a}}{V_{g}(1-D)}
$$

At the end of $t_{3}$, turn-off of the auxiliary switch $S_{a}$ is therefore lossless (ZCS). Following the interval $T_{3}$, the gate drive to the auxiliary switch may be turned-off.

Interval $4\left(t_{4}<t<t_{5}\right)$ : The main switch $\mathrm{S}$ is switchedoff at $t=t_{4}$ i.e at the end of $D T_{S}$. The turn-off of the main switch is at zero voltage, on account of capacitor across the main switch. The voltage across the switch raises slowly thereby reducing the turn-off transition losses.

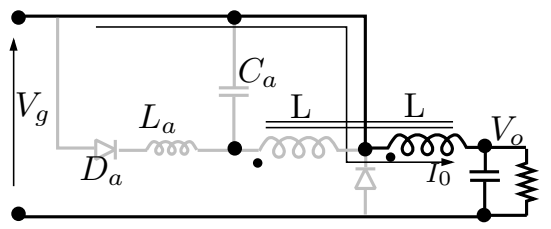

Fig. 14. ZVS buck converter: End of commutation

It is observed that turn-on and turn-off transitions of main switch and auxiliary switch are loss-less.

\section{Steady state experimental Results}

The circuit diagram is shown in Fig. 15. Following is the specifications of the prototype: Input voltage $V_{g}=18-25$ $\mathrm{V}$, Output voltage $V_{o}=30 \mathrm{~V}$, Output power $P_{o}=33 \mathrm{~W}$, Switching frequency $F_{S}=400 \mathrm{KHz}$. Simulation results and experimental results are shown in Fig. 16 and Fig. 17 respectively for the boost converter with coupled inductor. 

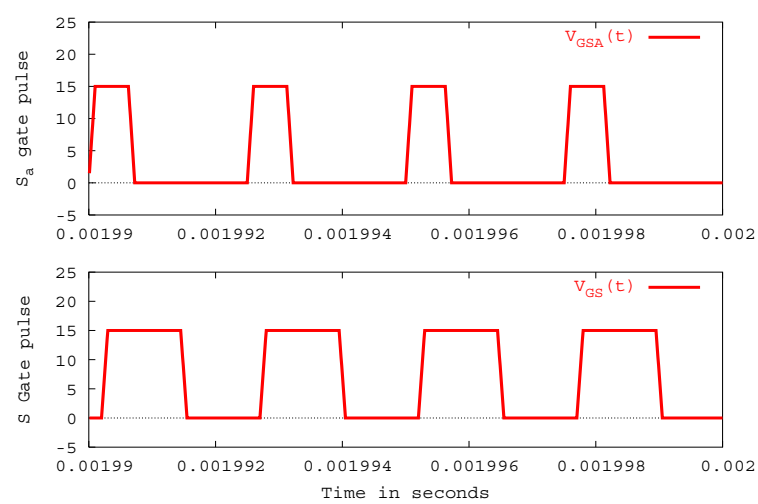

(a) $V_{g s a}$ and $V_{g s}$ of auxiliary switch $S_{a}$ and and active switch S

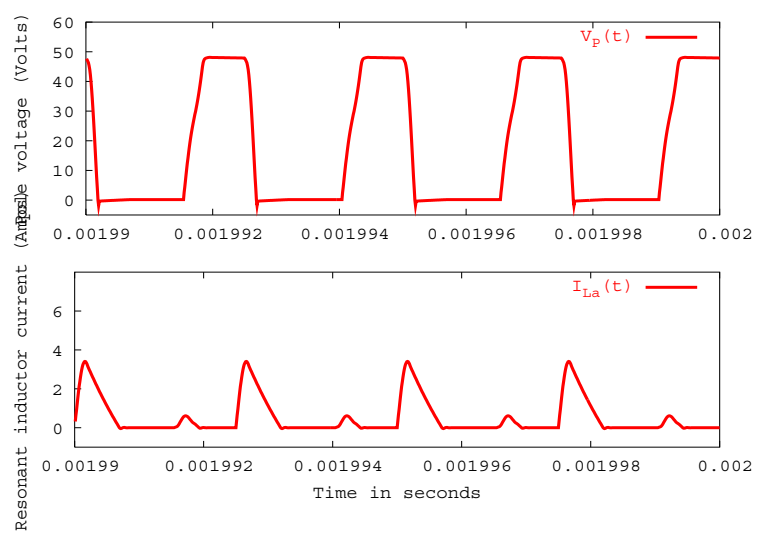

(b) pole voltage $V_{p}$ and resonant inductor current $i_{L a}(t)$

Fig. 16. Simulated waveforms of boost converter with tapped-coupled inductor

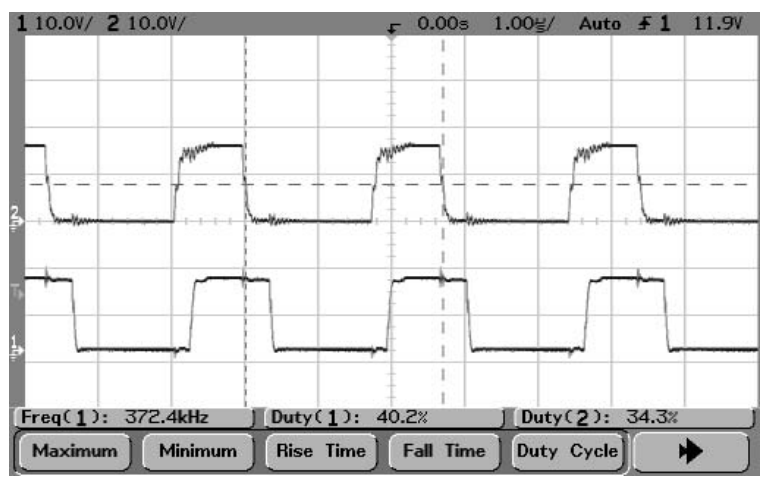

(a) Ch1: 10 volts/div ; Ch2: 10 volts/div $: V_{g s a}$ and $V_{g s}$ of auxiliary switch $S_{a}$ and active switch S

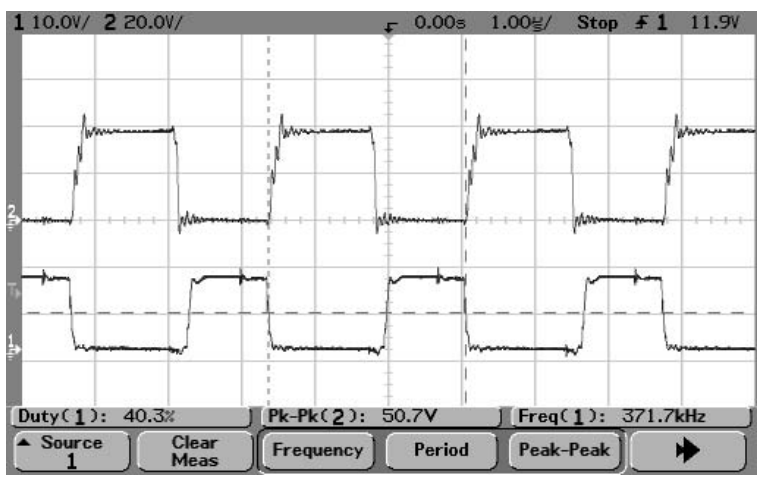

(c) Ch2: 20 volts/div ; Ch1: 10 volts/div $: V_{d s}$ and $V_{g s}$ of active switch $\mathrm{S}$ indicating ZVS turn-on

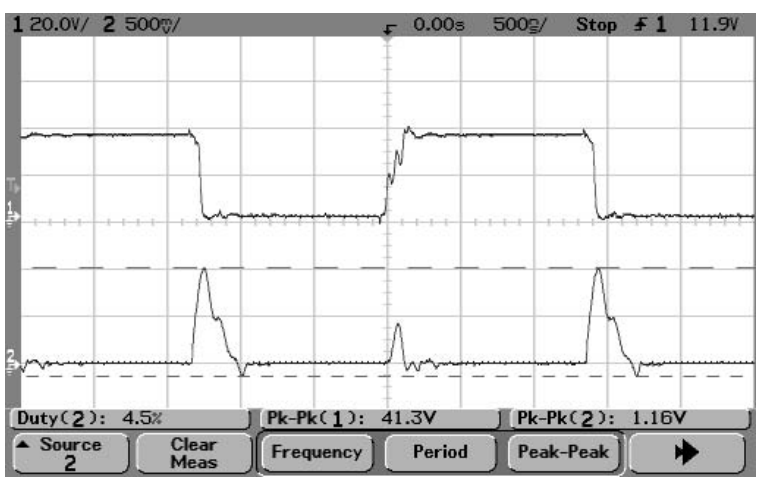

(b) Ch1: 20 volts/div ; Ch2: 0.5 volts/div :pole voltage $V_{p}$ and resonant inductor current $i_{L a}(t)$

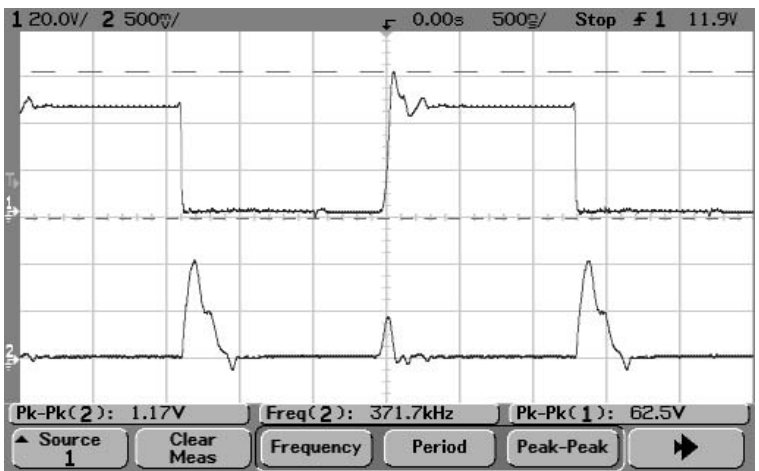

(d) Ch2: 20 volts/div ; Ch1: 0.5 volts/div $: V_{d s a}$ and $i_{S a}(t)$ of auxiliary switch indicating ZCS

Fig. 17. Experimental waveforms of boost converter with tapped-coupled inductor 


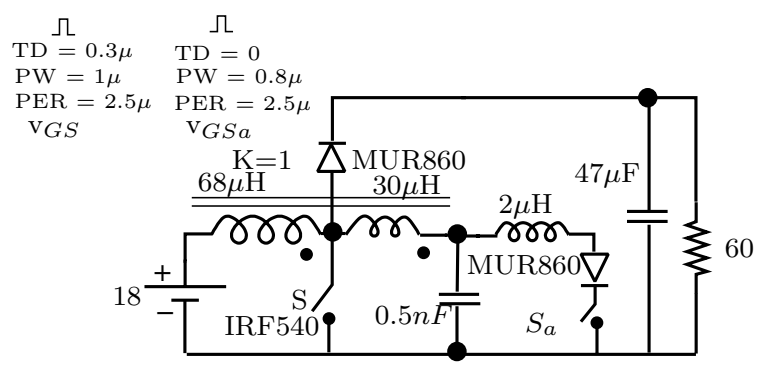

Fig. 15. Simulated boost converter with coupled inductor

1. Fig. 17(a) shows the gate pulses of frequency $400 \mathrm{KHz}$ driving $\mathrm{S}$ and $S_{a}$.

2. Fig. 17(b) shows the pole voltage and the resonant inductor current waveforms. In theoretical and simulated waveforms [Fig. 9 and Fig. 16(b)], there is a linear resetting of the resonant inductor current. In the experimental results, high frequency oscillations are observed during the resetting interval, due to parasitics of the resonant inductor.

\section{Steady state EFficiency Results}

Steady state efficiency results of hard switched boost converter and boost converter with the proposed auxiliary switch are compared [Table. I]. Efficiency as high as $94 \%$ is achieved for the boost converter, switching at $400 \mathrm{KHz}$.

TABLE I

STEADy STATE EFFICIENCY FOR THE HARD SWITCHED AND SOFT SWITCHED BOOST CONVERTER (WITH AUXILIARY SWITCH)

\begin{tabular}{ccc}
\hline Load $($ p.u) & Hard switched $(\% \eta)$ & Soft switched $(\% \eta)$ \\
\hline 0.35 & 72 & 78 \\
0.49 & 73 & 80 \\
0.62 & 78 & 84 \\
0.74 & 84 & 88 \\
0.89 & 87 & 91 \\
1 & 89 & 94 \\
\hline
\end{tabular}

\section{Application to other circuits}

This proposed method is applicable to all DC-DC converters. Some of the realizations are shown [Fig. 18 - 21].

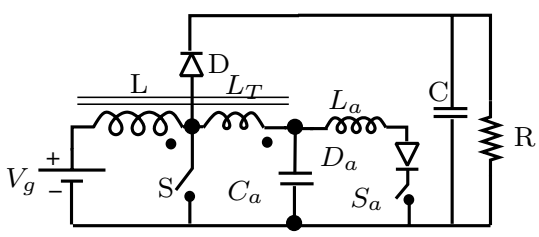

Fig. 18. Boost converter with coupled inductor

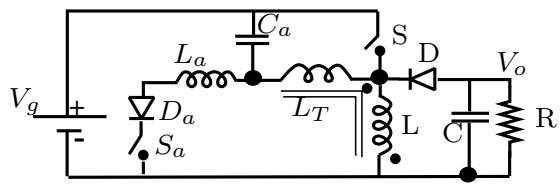

Fig. 19. Buck-boost converter with coupled inductor

\section{Conclusion}

A novel auxiliary switch DC-DC converter with coupled inductor is presented in this paper. The proposed

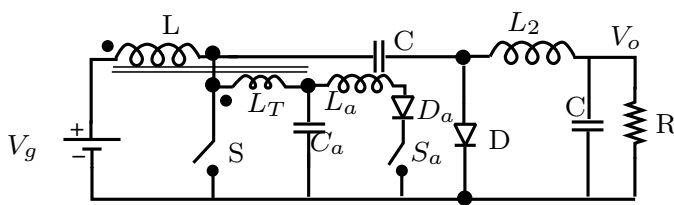

Fig. 20. Cuk converter with coupled inductor

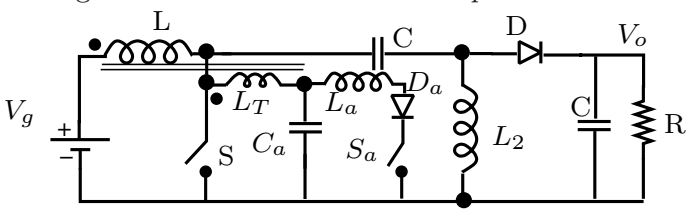

Fig. 21. Sepic converter with coupled inductor

circuit achieves loss-less switching for both the main and auxiliary switches without increasing the main device current/voltage rating. A tapping in the pole inductor is added for the purpose of commutation. The novelty in the proposed circuit is the method of generation of the auxiliary voltage needed to reset the ZVS circuit. The proposed circuit can be applied to all DC-DC converters (Buck, Boost, Buck-boost, Cuk, Sepic converters). The performance and the design equations are identical for all types of DC-DC converters when the equations are written in terms of throw voltage and the pole current. The method of analysis is outlined for a buck converter with coupled inductor. Simulation and experimental results are presented for a 33 watt, $400 \mathrm{KHz}$ boost converter.

\section{Acknowledgments}

The work, reported in this paper was supported by a research grant from Indian space research organization.

\section{REFERENCES}

[1] Middlebrook, R.D., and Sloobodan Cuk, 'Advances in SwitchedMode Power Conversion', Volumes I and II, 2nd Edition, TESLOco, 1983'

[2] Vatche Vorperian, 'Analysis of Resonant Converters', Ph. D. Thesis, California Institute of Technology, Pasadena, 1984.

[3] T.Zheng, D.Y. Cheng and F.C Lee, 'Variation of quasi-resonant DC/DC converter topologies' PESC, pp. 381-392, 1986.

[4] Freeland, S., Middlebrook, R.D., 'A Unified Analysis of converters with Resonant Switches', PESC, pp. 20-30, 1987.

[5] R.W. DeDoncker and J.P. Lyons, 'The Auxiliary Resonant Commutated Pole Converter', IAS, pp. 1228-1235, 1990.

[6] G.Hua, C.S.Leu, and F.C Lee, 'Novel Zero voltage Transition PWM converter', IEEE Transactions on Power Electronics, , vol. 9, pp. 213-219, 1994.

[7] Claudio Manoel C. Duarte and Ivo Barbi, 'A Family of ZVSPWM active clamping DC-to-DC Converters: Synthesis, Analsyis and Experimentation', INTELEC, pp.502-509, 1995.

[8] Yingqi Zhang, P.C. Sen Fellow IEEE, Yan-Fei Liu, 'A Novel Zero voltage switched (ZVS) Buck Converter using Coupled inductor', Canadian Conference of Electrical and Computer Engineering, pp. 357-362, 2001.

[9] Lakshminarasamma N, Swaminathan B, Ramanarayanan V, 'A unified Model for ZVS DC to DC Converters with Active Clamp', PESC, pp. 2441-2447, 2004.

[10] da Silva Martins, M.L, and Hey, H.L., 'Self Commutated Auxiliary Circiut ZVT PWM Converters', IEEE Transactions on Power Electronics, , vol. 19, pp. 1439-1445, 2004.

[11] Wang, C.M., 'Novel Zero-Voltage-Transition PWM DC-DC Converters', IEEE Transactions on Industrial Electronics, , vol. 53, pp. 254-262, 2006.

[12] V.Ramanarayanan, 'Invention Declaration on Auxiliary Commutation Circuits' Indian Institute of Science, 10 Feb 2006. 